\title{
Bedside Tracheostomy on Pediatric ICU Subjects Supported by Extracorporeal Membrane Oxygenation
}

\author{
Stephanie P Schwartz MD, Desiree Bonadonna CCP LP, Matthew G Hartwig MD, and \\ Ira M Cheifetz MD FAARC
}

\begin{abstract}
BACKGROUND: Tracheostomy facilitates ambulatory extracorporeal membrane oxygenation (ECMO) as a bridge to recovery or lung transplantation in patients with respiratory failure, yet data on this procedure in this population are lacking. This report describes a series of pediatric ICU patients who had a bedside tracheostomy performed while being supported on ECMO and examines the potential impact of this procedure on active rehabilitation and sedation requirements. METHODS: This retrospective case series reviews all patients in the pediatric ICU who received a tracheostomy while being supported on ECMO at a single tertiary care center for the past $3 \mathrm{y}$. This descriptive report reviews the surgical procedure, anticoagulation management, adjustments to sedation, and complications. RESULTS: Nine subjects between January 2013 and December 2015 were identified for review. The subjects ranged in age from $7 \mathrm{y}$ to $25 \mathrm{y}$. All tracheostomies were performed as bedside procedures in the pediatric ICU. All subjects but one were supported by venovenous ECMO. Surgical approaches included open tracheostomy ( 2 subjects, $22 \%$ ), percutaneous tracheostomy (1 subject, $11 \%$ ), and a hybrid approach (6 subjects, 67\%). Anticoagulation was held for all subjects surrounding the procedure. Three subjects had superficial bleeding after the procedure, but only one required re-exploration of the surgical field. All subjects made substantial sedation weans within $72 \mathrm{~h}$ of tracheostomy. With these weans, subjects were better able to participate in rehabilitation. Five subjects $(55.6 \%)$ ambulated on ECMO. The rate of survival to hospital discharge was $67 \%$, and no deaths were related to the tracheostomy procedure. CONCLUSIONS: Bedside tracheostomy can feasibly be performed on pediatric patients being supported with ECMO as a way to improve mobility, promote ambulation, and decrease sedation. Timing and ideal surgical approach require further study to fully maximize benefits and minimize risks. Key words: extracorporeal membrane oxygenation; tracheostomy; pediatrics; lung transplant; rehabilitation; respiratory failure; mechanical ventilation; hypoxia; hypercapnia; acute lung injury. [Respir Care 2017;62(11):1447-1455. (c) 2017 Daedalus Enterprises]
\end{abstract}

\section{Introduction}

Since its initial successful use in 1971, extracorporeal membrane oxygenation (ECMO) has seen a dramatic in-

\footnotetext{
Drs Schwartz and Cheifetz are affiliated with the Division of Pediatric Critical Care Medicine, Department of Pediatrics, Duke Children's Hospital, Durham, North Carolina. Ms Bonadonna is affiliated with Perfusion Services at Duke University Medical Center, Durham, North Carolina. Dr Hartwig is affiliated with the Division of Thoracic Surgery, and Dr Cheifetz is affiliated with Respiratory Care Services, at Duke University Medical Center, Durham, North Carolina.
}

The authors have disclosed no conflicts of interest.

Correspondence: Stephanie P Schwartz MD, Division of Pediatric Critical Care, DUMC Box 3046, Durham, NC 27710. E-mail: stephanie.permar@duke.edu.

DOI: $10.4187 /$ respcare. 05442 crease in utilization and successful outcomes in critically ill patients with cardiac and/or respiratory failure. ${ }^{1-4}$ Due to the lifesaving nature of this technology, as well as steady technological and strategic improvements, physicians are able to care for increasingly sicker populations of patients with ECMO. ${ }^{3,5-7}$ Deconditioning and muscle weakness, common in critically ill patients, can be further exacerbated in pediatric patients requiring ECMO secondary to traditional sedation practices, immobility, and cannulation techniques. ${ }^{8,9}$

Given the high morbidity associated with ICU myopathy coupled with improved ECMO technologies, which allow for easier movement, data support decreasing sedation and allowing awake ECMO patients to participate in physical therapy and ambulation.9-13 Early rehabilitation improves patient outcomes in the setting of critical illness. ${ }^{14,15}$ The safety of rehabilitation on $\mathrm{ECMO}^{9,10,12,16}$ and the potential advantages of minimizing sedation on $\mathrm{ECMO}^{9,11}$ have been published by several centers. Initial 


\section{Bedside Tracheostomy During ECMO in the PICU}

literature described success with ambulatory ECMO in adult populations, ${ }^{10}$ and recent case reports have supported the use of ambulatory ECMO in awake pediatric patients. ${ }^{17-20}$ Ambulatory ECMO decreases critical illness myopathy, length of stay, and duration of ventilation, and it increases survival. ${ }^{9}$

Tracheostomy is often one of the first steps in facilitating ambulatory ECMO as a bridge to recovery or lung transplantation in patients with respiratory failure.$^{10}$ Tracheostomy placement helps optimize secretion clearance and facilitate weaning of both sedation and mechanical ventilation, thus enhancing rehabilitation. ${ }^{10,17,21,22}$

Tracheostomy is a common procedure in adult ICUs, and studies have shown improved outcomes in morbidity and length of stay as compared with intubation. ${ }^{23,24}$ However, the pediatric literature shows that the procedure is less common, and there is little consensus on best practice and timing. ${ }^{25-27}$ Furthermore, there are bleeding risks when performing procedures on ECMO patients. Clinicians need to weigh the risks of bleeding associated with tracheostomy placement in anticoagulated patients versus the risks of holding anticoagulation and, thus, potentially causing clot formation in the ECMO circuit or thromboembolic complications. Performing a tracheostomy on a critically ill patient outside of the operating room setting can also be considered a risk, as pediatric tracheostomies typically occur as open procedures in an operating room.

In this report, we describe a single center's experience with tracheostomies performed via bedside procedures in the pediatric ICU on a wide variety of critically ill subjects supported with ECMO.

\section{Methods}

With institutional review board approval, we retrospectively identified all pediatric ICU patients who received a tracheostomy while being supported with ECMO at Duke University Medical Center from January 2013 to December 2015. The medical records of these subjects were reviewed with attention to demographics, underlying diagnosis, anticoagulation, operative reports, procedural complications, adjustments to anticoagulation, sedation, mobility, and outcomes at hospital discharge. A descriptive report is provided from this case series.

With regard to subjects who ambulated while receiving ECMO, Duke University Medical Center's rehabilitation program has been previously described. ${ }^{9,10}$ In brief, rehabilitation begins with resistance exercises, then progresses to sitting, standing, and, ultimately, ambulation. Sessions occur twice per day, as tolerated by the patient. Staffing during these sessions generally consists of an ECMO specialist, a respiratory therapist, a physical therapist, and bedside nurses. ${ }^{9,10}$

\section{QUICK LOOK}

\section{Current knowledge}

Tracheostomy facilitates ambulatory extracorporeal membrane oxygenation (ECMO) as a bridge to recovery or lung transplantation in patients with respiratory failure, yet data on this procedure in this population are lacking. Given the high morbidity associated with ICU myopathy coupled with improved ECMO technologies that allow for easier movement, data support decreasing sedation and allowing awake ECMO patients to participate in physical therapy.

\section{What this paper contributes to our knowledge}

Bedside tracheostomy can feasibly be performed on a broad range of patients being supported with ECMO in a pediatric ICU. This bedside procedure can facilitate decreased sedation and improved mobility and ambulation, thus allowing more active participation in early rehabilitation.

\section{Results}

We identified 9 subjects who received a tracheostomy while being supported with ECMO during the 3-y study period. All subjects were managed in the pediatric ICU during their ECMO course. All tracheostomies were performed at the bedside in the pediatric ICU. Table 1 summarizes key demographic features of the 9 subjects. The subjects ranged in age from $7 \mathrm{y}$ to $25 \mathrm{y}$. The etiology for the respiratory failure, ARDS, and need for ECMO support included infectious etiologies, underlying rheumatologic conditions, and cystic fibrosis. Subjects 1, 2, 3, and 9 were previously healthy with no significant past medical history. Four subjects (44.4\%) received bilateral orthotopic lung transplants. Two subjects $(22.2 \%)$ survived as a bridge to recovery, and 6 subjects $(66.6 \%)$ were alive at hospital discharge. No deaths were related to the tracheostomy procedure.

\section{Type of Tracheostomy Procedure}

As demonstrated in Table 2, the bedside procedure for tracheostomy placement varied between subjects. Surgical approach included open tracheostomy ( 2 subjects, $22.2 \%$ ), percutaneous tracheostomy (1 subject, $11.1 \%$ ), and hybrid approach (6 subjects, 66.7\%). The open approach included a mid or transverse cervical incision with sharp and electric dissection to the anterior tracheal wall. The trachea was incised with a trapdoor incision, and the tracheostomy tube was inserted. The percutaneous approach involved a 
Bedside Tracheostomy During ECMO in the PICU

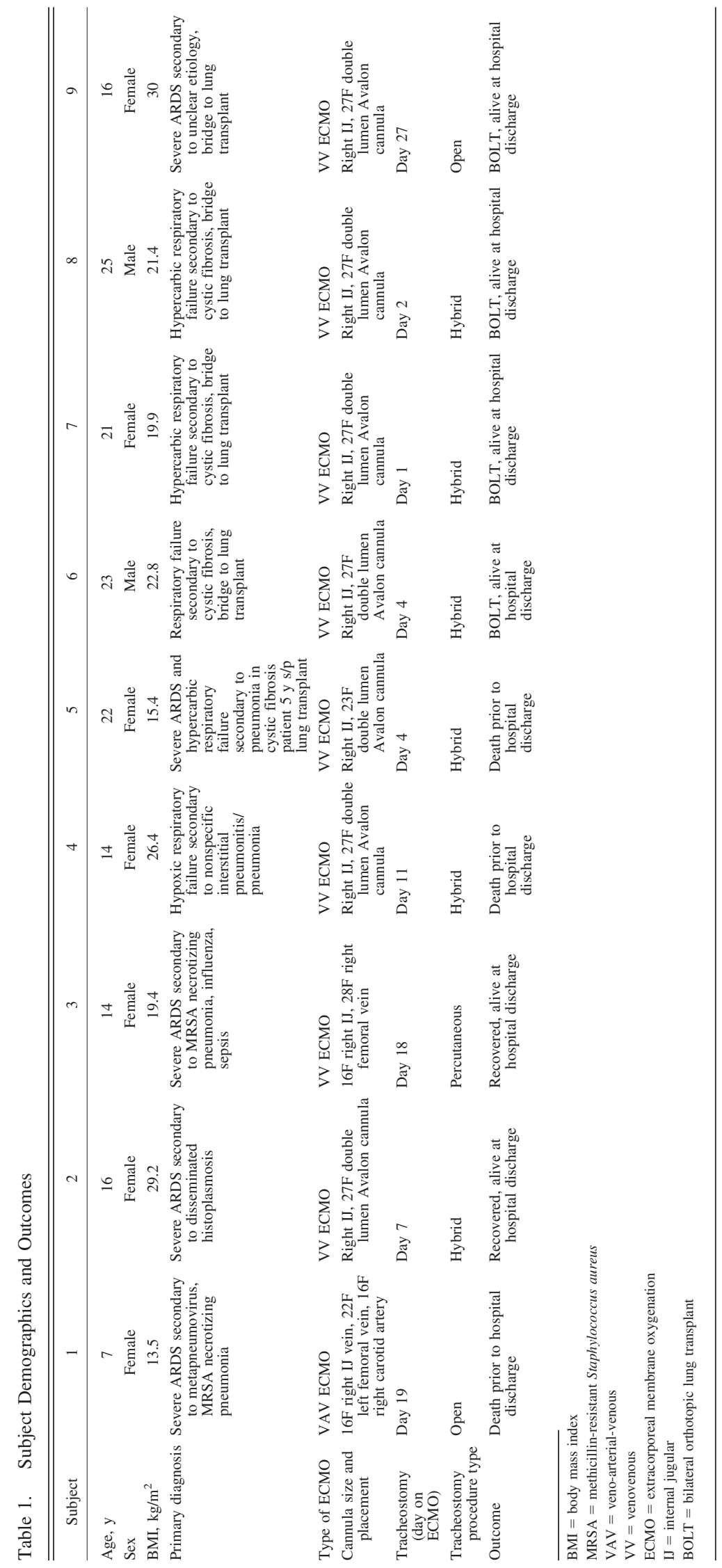




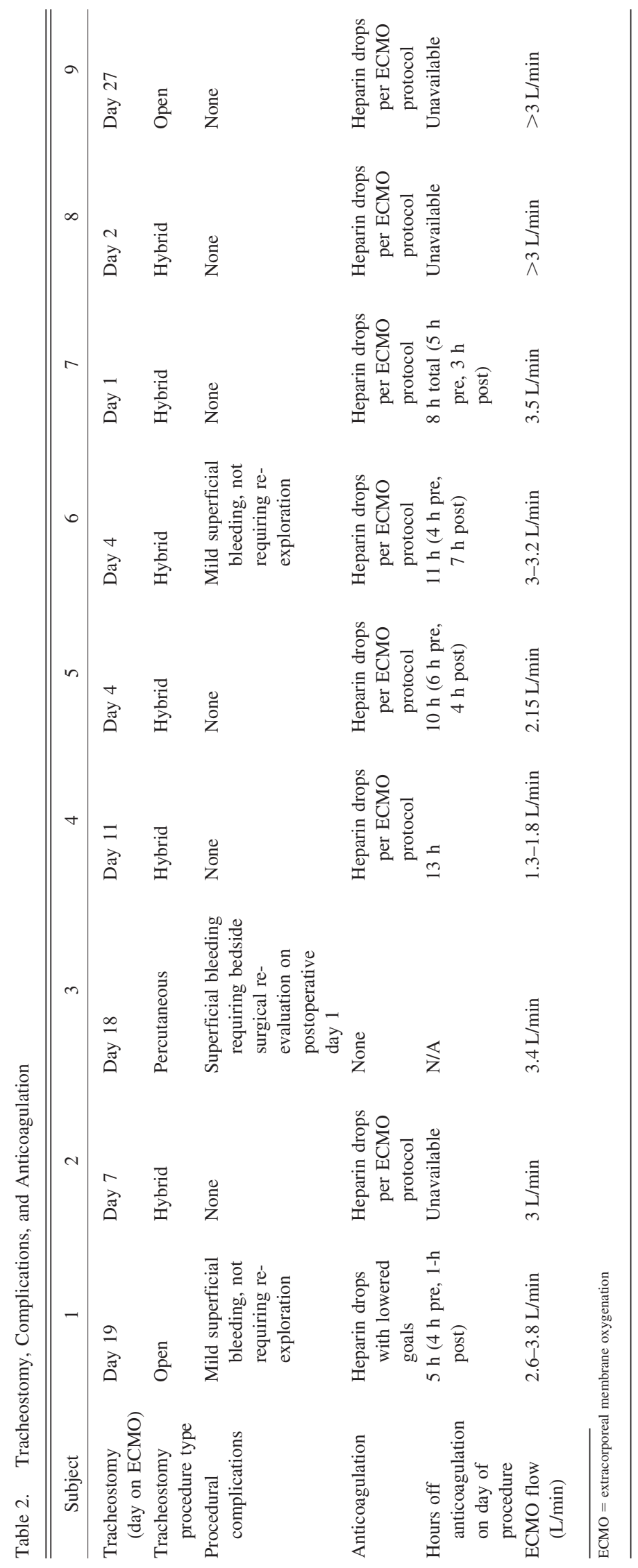




\section{Bedside Tracheostomy During ECMO in the PICU}

smaller skin incision with only blunt dissection to the anterior trachea, and then insertion of the tracheostomy with bronchoscopic guidance using serial dilation over a wire. The hybrid method employed sharp and electric dissection through the soft tissue to minimize bleeding risk, followed by placement of the tracheostomy using dilators over a wire. Three subjects had superficial bleeding after the tracheostomy; one subject (subject 3), who received a percutaneous tracheostomy, required re-exploration of the surgical field. Subjects 1 and 4, who had open and hybrid procedures, respectively, had mild superficial bleeding that did not require intervention or additional blood products. Timing of tracheostomy ranged from ECMO day 1 to ECMO day 27.

\section{Anticoagulation}

Per unit protocol, subjects were anticoagulated for ECMO using unfractionated heparin with a goal heparin level of $0.4-0.7 \mathrm{U} / \mathrm{mL}$ and a goal partial thromboplastin time of 60-80 s. Per discussion with the attending surgeon performing the bedside tracheostomy, anticoagulation was held the morning of the tracheostomy procedure and resumed after the procedure when deemed appropriate by the ICU and surgical teams. Total time off anticoagulation ranged from $5 \mathrm{~h}$ to $13 \mathrm{~h}$. Pre-procedure anticoagulation was held for 4-5 h. Anticoagulation was held postprocedure for 1-7 $\mathrm{h}$ (Table 2). ECMO flows at the time of tracheostomy and during the time off anticoagulation are provided in Table 2. Flows were unchanged for the $72 \mathrm{~h}$ surrounding the procedure.

Subject 1 had decreased heparin and partial thromboplastin time goals $(0.3-0.5 \mathrm{U} / \mathrm{mL}$ and $50-70 \mathrm{~s}$, respectively) due to bleeding from the cannula sites and pulmonary hemorrhage prior to tracheostomy placement. After an open tracheostomy, anticoagulation was held on the evening of postoperative day 1 due to superficial bleeding. The subject was thought to have heparin-induced thrombocytopenia on postoperative day 2 and remained off anticoagulation until postoperative day 9 when the confirmatory serotonin release assay was negative. During this prolonged period without anticoagulation, ECMO flows were increased to $3.8 \mathrm{~L} / \mathrm{min}(150 \mathrm{~mL} / \mathrm{kg} / \mathrm{min})$. Subject 3 had significant sanguineous chest tube output and bloody endotracheal tube secretions prior to tracheostomy and was maintained on ECMO without anticoagulation from ECMO day 11 (pretracheostomy) through the remainder of her course. On postoperative day 1 , after an uncomplicated percutaneous tracheostomy, superficial bleeding surrounding the tracheostomy site was unable to be controlled with conservative measures, and the site was re-explored in the pediatric ICU. No discrete bleeding site was found. The area was well cauterized, and hemostasis was obtained. Bleeding was noted to significantly improve within the next 24 h. Subject 6 had mild superficial oozing after tracheostomy placed using a hybrid approach. Anticoagulation was held for a total of $11 \mathrm{~h}$ periprocedure. Bronchoscopy on postoperative day 4 demonstrated only mild oozing and friable tissue. Subjects 2, 4, 5, 7, 8, and 9 had no bleeding complications after bedside tracheostomy placement. Table 2 summarizes data regarding tracheostomy procedure and anticoagulation.

\section{Sedation Management and Physical Rehabilitation}

Sedation was decreased and mobility improved in all subjects after tracheostomy. Table 3 provides a summary of the sedation management. Subject 1 required numerous sedatives in the $18 \mathrm{~d}$ preceding tracheostomy. In addition to the continuous agents listed in Table 3, she received scheduled quetiapine and lorazepam. After tracheostomy, long-acting agents were started to prevent withdrawal, and sedation weaning began $48 \mathrm{~h}$ postprocedure. One week after tracheostomy, the subject was more awake and able to participate in physical therapy. Subject 2 was more awake and alert $24 \mathrm{~h}$ after tracheostomy due to sedation weaning. Sedation weans for subject 3 were initiated prior to surgery. She was no longer on a benzodiazepine infusion and followed commands prior to tracheostomy. However, she frequently coughed and gagged on her endotracheal tube, limiting further sedation weans. At $48 \mathrm{~h}$ after re-exploration for bleeding, the subject was fully interactive with physical therapy and nursing staff and stated she appreciated the tracheostomy given her prior discomfort with the endotracheal tube. Subject 4 received risperidone in addition to the continuous agents listed in Table 3 . Sedation weaning was initiated and long-acting agents added to prevent withdrawal $24 \mathrm{~h}$ after surgery. Sedation weans for subject 5 began on the day of tracheostomy, and she was able to walk with ECMO support $24 \mathrm{~h}$ after a hybrid tracheostomy. Sedation weaning for subject 6 began the day of surgery and $48 \mathrm{~h}$ postprocedure all continuous intravenous agents were discontinued with oral pain medicines used as needed. He ambulated on ECMO $3 \mathrm{~d}$ after tracheostomy. Sedation weaning for subject 7 started on the day of tracheostomy and successfully concluded $24 \mathrm{~h}$ postprocedure. On the day of tracheostomy, subject 8 was sedated with numerous agents including continuous opioids, benzodiazepines, and propofol. Continuous benzodiazepines were discontinued by $96 \mathrm{~h}$ after tracheostomy, and the continuous opioid infusion was discontinued $4 \mathrm{~d}$ later. He remained on low dexmedetomidine $(0.4 \mu \mathrm{g} /$ $\mathrm{kg} / \mathrm{h}$ ) until transplant. Subject 9 required deep pharmacologic sedation and intermittent neuromuscular blockade throughout the initial ECMO course. Long-acting agents were added $24 \mathrm{~h}$ prior to her open tracheostomy. Continuous agents were fully weaned after the procedure, and she ambulated on ECMO $20 \mathrm{~d}$ after tracheostomy. 


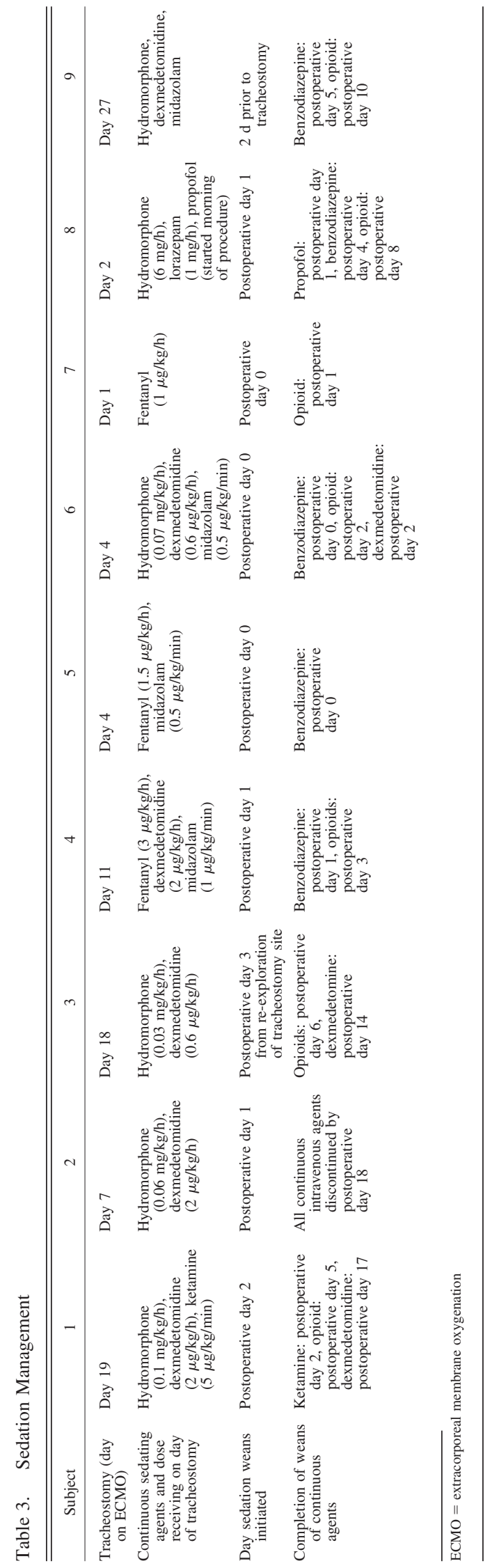

A multidisciplinary team, including physical therapists, occupational therapists, nursing staff, respiratory therapists, ECMO specialists, and physicians, worked with all subjects. Eight subjects (88.9\%) returned to neurological baseline and were fully interactive with staff and family prior to decannulation or death. Subject 4 did not return to full neurological baseline but could respond to simple commands after tracheostomy. Five subjects (subjects 5, 6, 7, 8 and 9) ambulated on ECMO (55.6\%).

\section{Decannulation Data}

Five subjects $(55.6 \%)$ were decannulated from tracheostomy prior to hospital discharge. Decannulation data are provided in Table 4.

\section{Discussion}

There is a growing body of literature that supports improved outcomes with ECMO when patients are awake and participate in active physical rehabilitation. $., 10,12,13,18,19$ Tracheostomy is an important procedure to facilitate decreased sedation and ultimately ambulation. Ours is the first case series to report the safe performance of bedside tracheostomies on critically ill pediatric ICU patients supported with ECMO.

Tracheostomy is a common procedure in adult ICUs, and studies have shown improved outcomes in morbidity and length of hospital stay compared with intubation. ${ }^{23,24}$ In the pediatric literature, however, the procedure is less common and there is little consensus on best practice and timing, ${ }^{25-27}$ especially in the ECMO population. While the Extracorporeal Life Support Organization (ELSO) guidelines recommend considering conversion to a tracheostomy early in the course in patients over $5 \mathrm{y}$ old to allow decreasing sedation, ${ }^{28}$ the pediatric ELSO guidelines acknowledge that tracheostomy is not often performed in pediatric patients. ${ }^{29}$ In our series, the decision of the timing of tracheostomy was made by the primary team's evaluation of anticipated timing of recovery, need for more aggressive rehabilitation, and sedation requirements.

Per ELSO guidelines, the primary need for sedation during venovenous ECMO is to tolerate the endotracheal tube. ${ }^{28}$ In this series, prior to tracheostomy, all subjects required continuous infusions of agents, which can lead to ICU myopathy and delirium. ${ }^{30,31}$ All subjects made substantial sedation weans within $72 \mathrm{~h}$ of tracheostomy. Posttracheostomy, all subjects were maintained on oral agents alone as needed for pain management or sleep, or on lowdose continuous infusions for analgesia and anxiety. With the posttracheostomy sedation reductions, subjects were better able to participate in their care and rehabilitation. Regarding mobility after tracheostomy, it has been our institution's practice to not walk patients who are intu- 


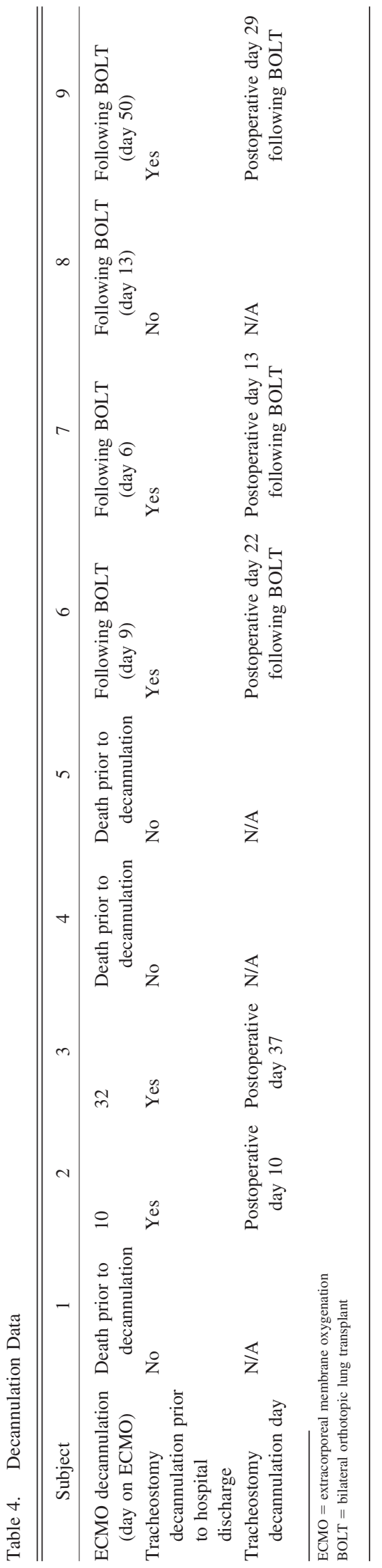

bated. Therefore, aggressive rehabilitation did not begin in our patient population until after bedside tracheostomy was performed. It should be noted that recent literature has included small case series reports of extubation on ECMO in a select population of pediatric and adult patients. ${ }^{13,32}$

Our series includes subjects with chronic lung disease cannulated with intent to transplant as well as subjects with acute illness cannulated as a bridge to recovery. One concern with decreasing sedation for previously healthy patients, particularly children, with acute lung injury is the anxiety and agitation associated with the novel feeling of air hunger. Patients with chronic respiratory insufficiency from diseases, such as cystic fibrosis, have a greater tolerance for dyspnea and have more frequently been reported with ambulatory ECMO.9-11,33 Our study supports previously published reports that previously healthy children ${ }^{18,19}$ can tolerate being awake on ECMO.

Family and nursing staff play a key role in supporting these pediatric patients as sedation is weaned. Sedation was weaned in all subjects in our series after the tracheostomy. All but one subject returned to their neurological baseline prior to decannulation, transplant, or death. These subjects, even those who ultimately would succumb to their disease, were able to have meaningful interactions with family and staff.

A review of the National In-patient Sample Database on adult patients supported with ECMO demonstrated that almost $50 \%$ of subjects supported with ECMO over a 4-y study period required a noncardiac surgical procedure, including tracheostomy, abdominal exploration, bowel resection, and thoracotomy, while being supported with ECMO. Those subjects requiring procedures were more likely to experience bleeding complications when compared to subjects not requiring surgical procedures. ${ }^{4}$

Despite the hematologic risks associated with performing surgical procedures on anticoagulated patients on ECMO, our series found no major complications after the procedure. Only one subject required re-exploration of the surgical field, and this was a subject with a history of significant bleeding who was being maintained on ECMO without anticoagulation. This subject received a percutaneous tracheostomy. Because of the theoretical increased risk from the percutaneous approach in anticoagulated patients, our institution's preference is to perform a standard open or hybrid approach for ECMO patients requiring tracheostomy. Ultimately, the attending physician performing the tracheostomy determines which technique will be performed. The other 2 subjects who had mild superficial bleeding did not require additional intervention after the procedures. Furthermore, in our case series there was no new clot formation in the ECMO circuit after withholding anticoagulation for the procedure.

All subjects in our case series had tracheostomies placed at the bedside in the pediatric ICU. Performing the proce- 


\section{Bedside Tracheostomy During ECMO in the PICU}

dure at the bedside eliminates the potential morbidity associated with moving critically ill patients to an operating room and limits costs. ${ }^{24,34}$ Furthermore, the critical care physicians, well versed in the patient's case, are available at the bedside without having to transition care to a different team.

This report has several limitations, most notably the small sample size and retrospective data collection from a single institution. We report subjects that comprise a pediatric ICU population, which includes young adults in addition to children. While young adults may receive care in a pediatric ICU, their physiology differs from younger children. Our results are consistent with the reported literature for tracheostomy in adult patients supported with ECMO and extends this observation to pediatric patients. In 2015, Camporota et $\mathrm{a}^{35}$ published a survey study of 133 adult ECMO centers in which $71 \%$ of centers reported performing tracheostomies on patients on ECMO. Timing of the tracheostomy varied and included tracheostomies performed prior to ECMO cannulation; $30 \%$ of adult ECMO centers responded to the survey that they never perform tracheostomies on patients on ECMO because of the risk of bleeding. Surveys often represent what clinicians think they "should do" and may not accurately reflect what they actually do. ${ }^{35,36}$ Additionally, this survey study did not include pediatric ECMO centers. Our study is based on actual clinical practice in a pediatric ECMO center over a 3-y period.

There are a number of clear challenges and risks that must be considered with any procedure performed on patients supported with ECMO, but our study demonstrates that tracheostomies can feasibly be performed at the bedside in a selection of pediatric ICU patients. Further studies are needed to identify the ideal surgical approach for bedside tracheostomies and the timing for the procedure to provide maximal benefit with decreased risk. Larger numbers of patients can provide a better understanding regarding specific time intervals to hold anticoagulation to ensure the lowest likelihood of both bleeding and thromboembolic complications.

\section{Conclusions}

We present the largest series of pediatric ICU subjects receiving a tracheostomy while being supported with ECMO. Our results demonstrate the feasibility of the bedside procedure in a broad range of pediatric ICU patients. This procedure can facilitate decreased sedation as well as improved mobility and ambulation through early rehabilitation.

\section{REFERENCES}

1. Bartlett RH, Gazzaniga AB, Jefferies MR, Huxtable RF, Haiduc NJ, Fong SW. Extracorporeal membrane oxygenation (ECMO) cardiopulmonary support in infancy. Trans Am Soc Artif Intern Organs 1976;22:80-93.
2. Hansell DR. Extracorporeal membrane oxygenation for perinatal and pediatric patients. Respir Care 2003;48(4):352-362, discussion 363-356.

3. Rehder KJ, Turner DA, Cheifetz IM. Extracorporeal membrane oxygenation for neonatal and pediatric respiratory failure: an evidencebased review of the past decade (2002-2012). Pediatr Crit Care Med 2013;14(9):851-861.

4. Taghavi S, Jayarajan SN, Mangi AA, Hollenbach K, Dauer E, Sjoholm LO, et al. Examining noncardiac surgical procedures in patients on extracorporeal membrane oxygenation. ASAIO J 2015; 61(5):520-525.

5. MacLaren G, Combes A, Bartlett RH. Contemporary extracorporeal membrane oxygenation for adult respiratory failure: life support in the new era. Intensive Care Med 2012;38(2):210-220.

6. Rehder KJ, Turner DA, Bonadonna D, Walczak RJ, Jr., Cheifetz IM. State of the art: strategies for extracorporeal membrane oxygenation in respiratory failure. Expert Rev Respir Med 2012;6(5):513-521.

7. Rehder KJ, Turner DA, Bonadonna D, Walczak RJ, Rudder RJ, Cheifetz IM. Technological advances in extracorporeal membrane oxygenation for respiratory failure. Expert Rev Respir Med 2012; 6(4):377-384

8. Griffiths RD, Hall JB. Intensive care unit-acquired weakness. Crit Care Med 2010;38(3):779-787.

9. Rehder KJ, Turner DA, Hartwig MG, Williford WL, Bonadonna D, Walczak RJ, Jr., et al. Active rehabilitation during extracorporeal membrane oxygenation as a bridge to lung transplantation. Respir Care 2013;58(8):1291-1298.

10. Turner DA, Cheifetz IM, Rehder KJ, Williford WL, Bonadonna D, Banuelos SJ, et al. Active rehabilitation and physical therapy during extracorporeal membrane oxygenation while awaiting lung transplantation: a practical approach. Crit Care Med 2011;39(12):2593-2598.

11. Fuehner T, Kuehn C, Hadem J, Wiesner O, Gottlieb J, Tudorache I, et al. Extracorporeal membrane oxygenation in awake patients as bridge to lung transplantation. Am J Respir Crit Care Med 2012; 185(7):763-768.

12. Abrams D, Javidfar J, Farrand E, Mongero LB, Agerstrand CL, Ryan $\mathrm{P}$, et al. Early mobilization of patients receiving extracorporeal membrane oxygenation: a retrospective cohort study. Crit Care 2014; 18(1):R38.

13. Raman L, Dalton HJ. Year in review 2015: extracorporeal membrane oxygenation. Respir Care 2016;61(7):986-991.

14. Schweickert WD, Pohlman MC, Pohlman AS, Nigos C, Pawlik AJ, Esbrook CL, et al. Early physical and occupational therapy in mechanically ventilated, critically ill patients: a randomised controlled trial. Lancet 2009;373(9678):1874-1882.

15. Morris PE, Griffin L, Berry M, Thompson C, Hite RD, Winkelman $\mathrm{C}$, et al. Receiving early mobility during an intensive care unit admission is a predictor of improved outcomes in acute respiratory failure. Am J Med Sci 2011;341(5):373-377.

16. Hayes D, Jr., Kukreja J, Tobias JD, Ballard HO, Hoopes CW. Ambulatory venovenous extracorporeal respiratory support as a bridge for cystic fibrosis patients to emergent lung transplantation. J Cyst Fibros 2012;11(1):40-45

17. Hayes D, Jr., Galantowicz M, Preston TJ, Lloyd EA, Tobias JD, McConnell PI. Tracheostomy in adolescent patients bridged to lung transplantation with ambulatory venovenous extracorporeal membrane oxygenation. J Artif Organs 2014;17(1):103-105.

18. Hayes D, Jr., Lloyd EA, Yates AR, McConnell PI, Galantowicz M, Preston TJ. Pediatric ambulatory ECMO. Lung 2014;192(6):1005.

19. Turner DA, Rehder KJ, Bonadonna D, Gray A, Lin S, Zaas D, et al. Ambulatory ECMO as a bridge to lung transplant in a previously well pediatric patient with ARDS. Pediatrics 2014;134(2):e583-e585.

20. Wong JY, Buchholz H, Ryerson L, Conradi A, Adatia I, Dyck J, et al. Successful semi-ambulatory veno-arterial extracorporeal mem- 


\section{Bedside Tracheostomy During ECMO in the PICU}

brane oxygenation bridge to heart-lung transplantation in a very small child. Am J Transplant 2015;15(8):2256-2260.

21. Arabi YM, Alhashemi JA, Tamim HM, Esteban A, Haddad SH, Dawood A, et al. The impact of time to tracheostomy on mechanical ventilation duration, length of stay, and mortality in intensive care unit patients. J Crit Care 2009;24(3):435-440.

22. Zagli G, Linden M, Spina R, Bonizzoli M, Cianchi G, Anichini V, et al. Early tracheostomy in intensive care unit: a retrospective study of 506 cases of video-guided Ciaglia Blue Rhino tracheostomies. J Trauma 2010;68(2):367-372.

23. Combes A, Luyt CE, Nieszkowska A, Trouillet JL, Gibert C, Chastre J. Is tracheostomy associated with better outcomes for patients requiring long-term mechanical ventilation? Crit Care Med 2007;35(3):802-807.

24. Kornblith LZ, Burlew CC, Moore EE, Haenel JB, Kashuk JL, Biffl $\mathrm{WL}$, et al. One thousand bedside percutaneous tracheostomies in the surgical intensive care unit: time to change the gold standard. J Am Coll Surg 2011;212(2):163-170.

25. Klotz DA, Hengerer AS. Safety of pediatric bedside tracheostomy in the intensive care unit. Arch Otolaryngol Head Neck Surg 2001; 127(8):950-955

26. Wood D, McShane P, Davis P. Tracheostomy in children admitted to paediatric intensive care. Arch Dis Child 2012;97(10):866-869.

27. Holloway AJ, Spaeder MC, Basu S. Association of timing of tracheostomy on clinical outcomes in PICU patients. Pediatr Crit Care Med 2015;16(3):e52-e58.

28. Extracorporeal Life Support Organization Guidelines for Cardiopulmonary Extracorporeal Life Support, version 1.3. http:// www.elsonet.org. Accessed January 19, 2017.
29. Extracorporeal Life Support Organization Pediatric Respiratory Failure Supplement to the ELSO General Guidelines, version 1.3. http:// www.elsonet.org. Accessed January 19, 2017.

30. Hermans G, Van den Berghe G. Clinical review: intensive care unit acquired weakness. Crit Care 2015;19:274.

31. Kudchadkar SR, Yaster M, Punjabi NM. Sedation, sleep promotion, and delirium screening practices in the care of mechanically ventilated children: a wake-up call for the pediatric critical care community. Crit Care Med 2014;42(7):1592-1600.

32. Anton-Martin P, Thompson MT, Sheeran PD, Fischer AC, Taylor D, Thomas JA. Extubation during pediatric extracorporeal membrane oxygenation: a single-center experience. Pediatr Crit Care Med 2014; 15(9):861-869.

33. Nosotti M, Rosso L, Palleschi A, Lissoni A, Crotti S, Marenghi C, et al. Bridge to lung transplantation by venovenous extracorporeal membrane oxygenation: a lesson learned on the first four cases. Transplant Proc 2010;42(4):1259-1261.

34. Ertugrul I, Kesici S, Bayrakci B, Unal OF. Tracheostomy in pediatric intensive care unit: when and where? Iran J Pediatr 2016;26(1): e2283.

35. Camporota L, Nicoletti E, Malafronte M, De Neef M, Mongelli V, Calderazzo MA, et al. International survey on the management of mechanical ventilation during ECMO in adults with severe respiratory failure. Minerva Anestesiol 2015;81(11):1170-1183.

36. Brunkhorst FM, Engel C, Ragaller M, Welte T, Rossaint R, Gerlach $\mathrm{H}$, et al. Practice and perception: a nationwide survey of therapy habits in sepsis. Crit Care Med 2008;36(10):2719-2725. 